injection before admission. In our series, however, $13 \%(4 / 31)$ of patients referred by doctors died when the diagnosis had been suspected, with $20 \%(2 / 10)$ dying when the diagnosis had not been suspected.

Anaphylactic reaction to penicillin does exist, but many patients are incorrectly labelled as being allergic to penicillin. ${ }^{12}$ Although concern has been expressed about the potential harm from the rapid release of endotoxins, ${ }^{10}$ there is no evidence to suggest that such early antibiotic therapy results in a poorer outcome. Despite the small size of the study, clinically important observations are emerging. We hope that others will be encouraged to publish their findings so that evidence may accumulate to clarify the situation further. This study shows the soundness of the recommendation to give parenteral penicillin to all patients with meningococcal disease on suspicion of the diagnosis before transfer to hospital, despite the loss of diagnostic precision resulting from such a strategy.

\section{PUBLIC HEALTH PERSPECTIVE}

Much effort is expended in identifying and treating close contacts of each index case with rifampicin and, where appropriate, with vaccine to prevent secondary cases of meningococcal disease. Transmission between patients is rare, however, secondary cases accounting for only $0 \cdot 8 \%$ of all cases of meningococcal infection reported to the Communicable Disease Surveillance Centre from 1978 to $1987 . .^{8}$ Although it remains important to continue this work to prevent secondary cases, this study shows that a more proactive approach by this directorate of public health medicine by means of an information and alerting campaign directed at family doctors has had a positive effect on the high case fatality rate from this disease. The agenda of every public health physician who has responsibility for the surveillance and control of communicable disease should include mounting such a campaign and monitoring its effect on penicillin prescribing before admission and on mortality in hospital. In September 1991 public health physicians throughout the Northern region participated in alerting all general practitioners and deputising services about the importance of early antibiotic treatment for all suspected cases. Future surveillance of meningococcal disease throughout the region will include recording penicillin prescribing before admission and outcome in terms of survival or death in hospital.

We thank Dr F S Pagan, consultant microbiologist, and al physicians and paediatricians at the Memorial Hospital, Darlington, for allowing access to patient records. We also thank Dr Hilary Tillett of the Public Health Laboratory Service for her critical comments and advice in the statistical analysis. The information and alerting campaign in Darlington was supported by the Dawn Craggs Meningitis Appeal Fund.

1 Office of Population Censuses and Surveys. Infectious diseases, 1980-9 London: HMSO, 1980-91. (Series MB2, No 80/3-91/1.)

2 Jones DM, Kaczmarski EB. Meningococcal infections in England and Wales: report of the Meningococcal Disease Reference Laboratory for 1990 Communicable Disease Report 1991;1:R76-8.

3 Havens PL, Garland JS, Brook MM, Dewitz BA, Stremski ES, Troshynski TJ. Trends in mortality in children hospitalised with meningococcal infections, 1957 to 1987. Paediatr Infect Dis 7 1989:8:8-11.

4 Bjune G, Hoiby EA, Gronnesby JK, Arnesen O, Fredriksen JH, Halstensen ,

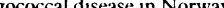

5 Department of Health. Immunisation against infectious disease. London: HMSO, 1990:166-72.

6 Cartwright KAV, Stuart JM, Noah ND. An outbreak of meningococcal disease in Gloucestershire. Lancet 1986;ii:558-61.

7 Department of Health and Social Security. Meningococcal infection: meningitis and septicaemia. London: $\mathrm{HMSO}, 1988$. (CMO(88) 2 .)

8 PHLS Meningococcal Infections Working Party. The epidemiology and control of meningococcal disease. Communicable Disease Report 1989;8:3-6. 9 Welsby PD, Golledge CI. Meningococcal meningitis. BMJ 1990;300:1150-1. 10 Hopkin DAB. Frapper fort ou frapper doucement: a Gram-negative dilemma. Lancet 1978;ii:1193-4.

11 Gedde-Dahl TW, Horby EA, Brandtzaeg P, Eskerud JR, Bovre K. Some arguments on early hospital treatment of suspected meningococcal diseas cases. NIPH Ann 1990;13:45-60.

12 Surtees SJ, Stockton MG, Gietzen TW. Allergy to penicillin: fable or fact? BMF 1991;302:1051-2.

\title{
Early treatment with parenteral penicillin in meningococcal disease
}

\author{
Keith Cartwright, Sheena Reilly, Diana White, James Stuart
}

Public Health Laboratory, Gloucestershire Royal Hospital, Gloucester GL1 3NN Keith Cartwright, director

Public Health Laboratory, Derriford Hospital, Plymouth PL6 8DH Sheena Reilly, consultant microbiologist

Public Health Laboratory, Royal United Hospital, Combe Park, Bath BA1 3NG

Diana White, director

\section{Gloucester Health}

Authority, Rikenel, Montpellier, Gloucester GL1 1LY

James Stuart, consultant in communicable disease control

Correspondence to: Dr Cartwright.

BMF 1992;305:143-7
Abstract

Objective-To measure the effect of parenteral antibiotics given before admission to hospital on mortality and on bacteriological investigations in meningococcal disease.

Design-Retrospective review of hospital notes and laboratory and public health medicine department records.

Setting-Three health districts in south west England.

Subjects-Patients with meningococcal disease in Gloucester district presenting between 1 January 1982 and 31 December $1991(n=190)$; patients with meningococcal disease in Plymouth $(n=118)$ and Bath $(n=73)$ districts presenting between 1 January 1988 and 31 December 1991 (total=381).

Main outcome measure-Number of deaths from meningococcal disease.

Results-Parenteral antibiotic given by general practitioners was associated with a substantial reduction in mortality (from $9 \%$ to $5 \%$; relative risk $0 \cdot 6,95 \%$ confidence interval 0.2 to $1 \cdot 5$ ); patients with a rash were more likely to be given parenteral antibiotics, and mortality was further reduced (from $12 \%$ to $5 \% ; 0.5,0.2$ to 1.4$)$. In a district where such treatment was regularly encouraged its use increased from $5 \%$ to $40 \%$ of cases over 10 years $(\mathbf{p}=0 \cdot 00001)$. Treatment with parenteral antibiotics before admission made isolation of meningococci from blood and cerebrospinal fluid less likely but did not affect nasopharyngeal cultures.

Conclusions-General practitioners should carry benzylpenicillin in their emergency bags at all times and should administer it promptly, preferably intravenously, whenever meningococcal disease is suspected, unless the patient has had an anaphylactic reaction to penicillin. Specimens for culture should include a nasopharyngeal swab.

\section{Introduction}

Data from the Office of Population Censuses and Surveys show that notifications of meningococcal disease in England and Wales rose in each year from 1984 to $1990 ; 460$ isolates from clinical cases were submitted to the Meningococcal Reference Laboratory in 1984, compared with 1500 in 1990 . Nearly all cases were due to strains of serogroups B and C.' Although serogroup A plus $C$ vaccines are available they confer only short term protection, are not adequately immunogenic in children, and are therefore not suitable for a universal immunisation programme. ${ }^{2}$ Serogroup $B$ vaccines are not sufficiently developed for widespread use at present. ${ }^{34}$ 
Most deaths from meningococcal disease seem to be recorded, 5 but substantial undernotification to the Office of Population Censuses and Surveys of cases in which the patient survives has been a problem for many years..$^{6-8}$ Underreporting probably also occurs when bacteriological confirmation of the diagnosis is lacking. For these reasons, national estimates of mortality are imprecise.

After a meningococcus is acquired it is usually carried transiently in the nasopharynx. ${ }^{9}$ Meningitis is the commonest clinical manifestation, but $10 \%$ or more of patients experience a predominantly septicaemic illness. In the United Kingdom the death rates in meningococcal meningitis and septicaemia are estimated to be $5-10 \%$ and $15-20 \%$ respectively. ${ }^{510}$ Shock, a petechial or purpuric rash, and reduced consciousness are all associated with a less favourable outcome. ${ }^{11-13}$ Mortality is higher in very young patients and elderly patients ${ }^{514}$ and in those in whom there has been diagnostic or therapeutic delay. ${ }^{13} 1516$

Early treatment of suspected meningococcal disease with antibiotics has been advocated for many years. ${ }^{15} 17$ This advice was promulgated to all doctors in the United Kingdom by the chief medical officer in $1988,{ }^{18}$ and this advice was widely disseminated again in 1989 in the Drug and Therapeutics Bulletin, ${ }^{19}$ although a beneficial effect on mortality of giving parenteral antibiotics before admission to hospital had not been formally shown.

Gloucester, Plymouth, and Bath health districts have all experienced high rates of meningococcal disease over the past 10 years. Throughout the Gloucester outbreak the staff of the department of public health medicine encouraged local general practitioners to give parenteral benzylpenicillin when meningococcal disease was suspected, before patients were transferred to hospital. In each district a register of cases was available in the local public health laboratory or department of public health medicine. We carried out a retrospective analysis of case notes of patients with a clinical or laboratory diagnosis of meningococcal disease to determine whether a parenteral antibiotic had been given to the patient before admission to hospital, what factors influenced the use of parenteral antibiotics by the general practitioner, and the effect of such early treatment on outcome and on bacteriological investigations.

\section{Methods}

Patients were accepted as having had meningococcal disease if $(a)$ a meningococcus had been isolated from blood or cerebrospinal fluid; $(b)$ clinical evidence of

TABLE I-Age and sex distribution of patients with meningococcal disease, Gloucester health district, 1982-91, and Bath and Plymouth health districts, 1988-91

\begin{tabular}{cccc}
\hline Age $($ years $)$ & Male patients & Female patients & Total \\
\hline$<1$ & 12 & 10 & 22 \\
$1-4$ & 64 & 42 & 106 \\
$5-9$ & 24 & 12 & 36 \\
$10-14$ & 15 & 18 & 33 \\
$15-19$ & 45 & 40 & 85 \\
$20-29$ & 27 & 13 & 40 \\
$\geqslant 30$ & 18 & 20 & 38
\end{tabular}

TABLE II - Diagnostic categories of cases of meningococcal disease. Values are numbers (percentages of total)

\begin{tabular}{|c|c|c|c|c|}
\hline Diagnostic category & Gloucester & Plymouth & Bath & Total \\
\hline Isolation (deep site) & $133(37)$ & $74(21)$ & $40(11)$ & $247(69)$ \\
\hline diplococci in cerobrospinal fluid & $18(5)$ & $9(3)$ & $5(1)$ & $32(9)$ \\
\hline Clinical (meningitis with haemorrhagic rash) & $25(7)$ & $19(5)$ & $12(3)$ & $56(16)$ \\
\hline $\begin{array}{l}\text { Meningitis or haemorrhagic rash, or both, with positive } \\
\text { nasopharyngeal swab or positive serology }\end{array}$ & $11(3)$ & $6(2)$ & $8(2)$ & $25(7)$ \\
\hline Total & $187(52)$ & $108(30)$ & $65(18)$ & $360(100)$ \\
\hline
\end{tabular}

meningitis had been accompanied by the presence of Gram negative diplococci in cerebrospinal fluid; $(c)$ signs and symptoms of meningitis or septicaemia had been accompanied by a haemorrhagic rash; or $(d)$ a haemorrhagic rash or clinical evidence of meningitis, or both, had been accompanied by isolation of a meningococcus from a nasopharyngeal swab, ${ }^{20}$ by a rise in meningococcal antibody, or the presence of $\operatorname{IgM}$ specific to meningococcus. ${ }^{21}$

The notes of all patients satisfying this case definition were reviewed for residents of Gloucester health $\overrightarrow{\vec{*}}$ district between 1 January 1982 and 31 December 1991 or of Plymouth or Bath health districts between 1 January 1988 and 31 December 1991. Residents of $\overline{\bar{c}}$. eastern Cornwall who met the case definition and $\overrightarrow{\widetilde{R}}$ who had been managed in Plymouth hospitals were included. Cases were excluded from analysis if thes patient had been transferred from another hospital $\vec{\circ}$ $(n=5)$, if the patient had been admitted to hospital as $a_{-}$ result of self referral $(n=4)$ or developed meningo- $\vec{\omega}$ coccal disease while in hospital $(n=2)$, or if the finalo diagnosis was chronic meningococcal sepsis $(n=4) 3$. Evidence of antibiotic treatment before admission wasi obtained from the general practitioner's referral letterur or from the admitting doctor's notes. The longero review period in Gloucester health district allowed measurement of the effectiveness of the information and education programme encouraging general practi- $-\omega$ tioners to give parenteral antibiotics to patients with suspected meningococcal disease before transfer to hospital.

Results of meningococcal cultures of blood, cerebro $\stackrel{\complement}{\stackrel{c}{<}}$ spinal fluid, and nasopharyngeal swabs were obtainedfrom hospital notes, supplemented by laboratory ande public health medicine department records. Results of cultures of nasopharyngeal swabs obtained by theo pernasal and oral routes were not differentiated. Patients were defined as surviving meningococcalo disease if they had been discharged alive from hospitalo at the end of the acute episode.

The $\chi^{2}$ test was used with Yates's correction. $\overrightarrow{\vec{B}}$ Relative risks were calculated with $95 \%$ confidence 3 intervals. Cases for which the relevant data were not? known were excluded from statistical analyses.0. Statistical calculations were carried out with Epi Info version 5.22

\section{Results}

After the 15 stated exclusions 366 patients met the case definition. The notes of six (one who survived and five who died) were not available, leaving 360 cases for analysis. Table I shows the age and sex distributions ofo these cases; these distributions were not significantly different from those of patients from England andE. Wales whose strains had been submitted to the Meningococcal Reference Laboratory over the period 1984-91, though there were relatively fewer patientso under the age of 1 year in the study population.

Of the 360 cases, 340 had been sent to hospital by के general practitioner and 20 had been admitted through an accident and emergency department. The diagnosiso of meningococcal disease had been based on isolation of the organism from blood or cerebrospinal fluid or on the presence of Gram negative diplococci in cerebrospinal fluid in 279 of 360 cases (78\%) (table II)

General practitioners had given parenteral antibiotics before admission to $93 / 340(27 \%)$ patients and 20 further $5 / 20(25 \%)$ had been so treated by a casualty officer before hospital admission. A rash had beero noted in $222(65 \%)$ of the 340 cases referred by a general practitioner; in $177(52 \%)$ the rash had been recorded by the general practitioner as purpuric or petechial. Parenteral antibiotics had been given before admission in $38 \%$ of cases with a rash compared with 
$8 \%$ of those without a rash (table III; $\chi^{2}=33 \cdot 1$, $\mathrm{p}<0.00001)$. A slightly higher proportion with haemorrhagic rash $(75 / 177,42 \%)$ had received antibiotics.

Four Plymouth patients had not been given parenteral penicillin before admission because they had a history of penicillin allergy. Though a presumed penicillin rash had sometimes occurred in the later stages of treatment, anaphylaxis did not result from antibiotic treatment before admission. The proportions of patients referred by general practitioners in Gloucester health district given parenteral antibiotics before admission increased progressively in three equal time periods between 1 January 1982 and 31 December 1991 (table IV).

The overall fatality rate in patients referred by general practitioners was $8 \%$ (table $\mathrm{V}$ ). There was a substantial, though not statistically significant, reduction in mortality when antibiotics had been given before admission, and a greater reduction still when the general practitioner had noted a haemorrhagic rash. Mortality was raised in patients aged under 1 year and over $30(8 / 58 v 20 / 282$, relative risk 1.94, 95\% confidence interval 0.90 to $4 \cdot 2$ ). Patients in these age groups were significantly less likely to have been given parenteral antibiotics before admission (5/58 $v$ 88/281; $\chi^{2}=11 \cdot 3, p=0 \cdot 0008$; table VI), and rashes were noted significantly less frequently by their general practitioners $\left(27 / 58 v 195 / 280 ; \chi^{2}=10 \cdot 4, \mathrm{p}=0 \cdot 001\right)$.

Blood cultures gave positive results in very few patients given parenteral antibiotics before admission and in half of those not given antibiotics (table VII). Microscopy and culture of cerebrospinal fluid were also less likely to have given positive results in patients

TABLE III -Skin rash and use of parenteral antibiotics before hospital admission

\begin{tabular}{lrrrr}
\hline & \multirow{2}{*}{$\begin{array}{c}\text { No }(\%) \text { of } \\
\text { patients }\end{array}$} & Present & Absent & Not known \\
\cline { 5 - 6 } & & & & \\
\hline Antibiotic: & $93(27)$ & $84(25)$ & $9(3)$ & $1(<1)$ \\
$\quad$ Given & $246(72)$ & $138(41)$ & $107(32)$ & $1(<1)$ \\
$\begin{array}{l}\text { Not given } \\
\text { Not known }\end{array}$ & $1(<1)$ & & & $1(<1)$ with skin rash \\
\hline Total & $340(100)$ & $222(65)$ & $116(34)$ & $2(1)$ \\
\hline
\end{tabular}

TABLE IV-Use of parenteral antibiotics before hospital admission in suspected meningococcal disease by general practitioners in Gloucester health district. Values are numbers (percentages) of patients

\begin{tabular}{lccc}
\hline & \multicolumn{3}{c}{ Period } \\
\cline { 2 - 4 } & $\begin{array}{c}\text { 1 January 1982- } \\
\text { 30 April 1985 }\end{array}$ & $\begin{array}{c}\text { 1 May 1985- } \\
\text { 31 August 1988 }\end{array}$ & $\begin{array}{c}\text { 1 September 1988- } \\
\text { 31 December 1991 }\end{array}$ \\
\hline $\begin{array}{l}\text { Antibiotic: } \\
\text { Given }\end{array}$ & $2(5)$ & $14(21)$ & $29(40)$ \\
$\begin{array}{l}\text { Not given } \\
\text { Not known }\end{array}$ & $42(95)$ & $54(79)$ & $43(60)$ \\
\hline Total & $1(>1)$ & & $72(100)$ \\
\hline
\end{tabular}

$\chi^{\prime}$ for trend $19 \cdot 6 ; p=0 \cdot 00001$

TABLE $\mathrm{v}-E$ Efect of parenteral antibiotics given before admission on mortality in patients sent to hospital by general practitioners

\begin{tabular}{|c|c|c|c|c|}
\hline & \multicolumn{2}{|c|}{$\begin{array}{l}\text { All cases } \\
(n=340)\end{array}$} & \multicolumn{2}{|c|}{$\begin{array}{c}\text { Cases with } \\
\text { haemorrhagic rash } \\
(\mathbf{n}=177)\end{array}$} \\
\hline & $\begin{array}{c}\text { No }(\%) \\
\text { survived }\end{array}$ & $\begin{array}{l}\text { No }(\%) \\
\text { died }\end{array}$ & $\begin{array}{c}\text { No }(\%) \\
\text { survived }\end{array}$ & $\begin{array}{c}\text { No }(\%) \\
\text { died }\end{array}$ \\
\hline \multicolumn{5}{|l|}{ Antibiotic: } \\
\hline Given & $88(95)$ & $5(5)$ & $71(95)$ & $4(5)$ \\
\hline Not given & $224(91)$ & $22(9)$ & $90(88)$ & $12(12)$ \\
\hline Not known & & 1 & & 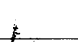 \\
\hline Total & $312(92)$ & $28(8)$ & $161(91)$ & $16(9)$ \\
\hline $\begin{array}{l}\text { Relative risk ( } 95 \% \\
\text { confidence interval) }\end{array}$ & \multicolumn{2}{|c|}{$0.60(0.23$ to 1.54$)$} & \multicolumn{2}{|c|}{$0.45(0.15$ to 1.35$)$} \\
\hline
\end{tabular}

TABLE VI-Mortality and use of parenteral antibiotics before hospital admission in patients with meningococcal disease

\begin{tabular}{cccc}
\hline Age (years) & $\begin{array}{c}\text { No of } \\
\text { patients }\end{array}$ & $\begin{array}{c}\text { No }(\%) \\
\text { who died }\end{array}$ & $\begin{array}{c}\text { No }(\%) \text { given } \\
\text { antibiotics }\end{array}$ \\
\hline$<1$ & 21 & $3(14)$ & $1(5)$ \\
$1-4$ & 100 & $9(9)$ & $31(31)$ \\
$5-9$ & 33 & $4(12)$ & $12(36)$ \\
$10-14$ & 29 & $1(3)$ & $9(31)$ \\
$15-19$ & 83 & $3(4)$ & $26(31)$ \\
$20-29$ & 36 & $3(8)$ & $10(28)$ \\
$\geqslant 30$ & 37 & $5(14)$ & $4(11)$ \\
\hline
\end{tabular}

TABLE VII-Effect of parenteral antibiotics given before hospital admission on microbiological investigations (all patients)

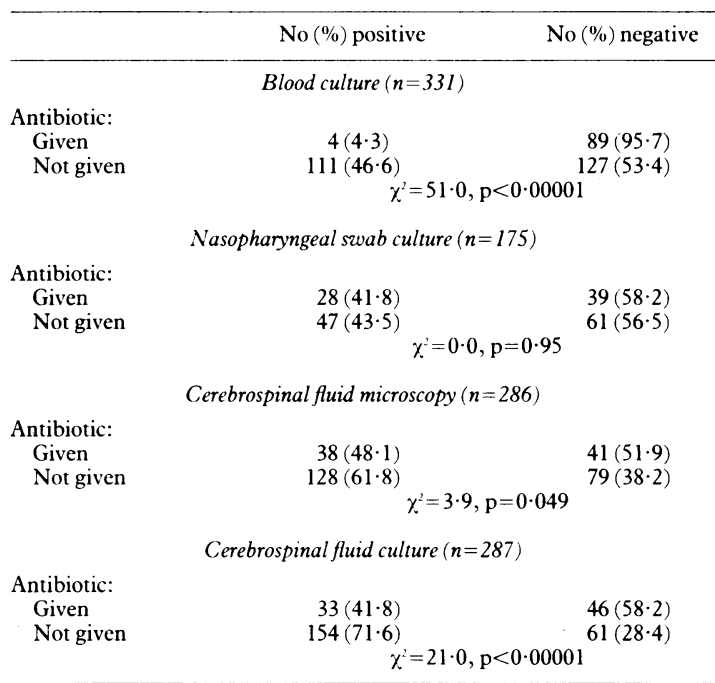

given parenteral antibiotics before admission, but the differences were less great; the meningococcal isolation rate from nasopharyngeal swabs was similar in the two groups.

\section{Discussion}

In this study the case fatality rate for meningococcal disease was reduced by $40 \%$ when general practitioners had given parenteral antibiotics before the patients were admitted to hospital; the reduction in mortality was greater than $50 \%$ when a haemorrhagic rash had been observed; these patients were most likely to receive antibiotics before admission. A petechial or purpuric rash had been recorded in 53\% of patients with meningococcal disease before hospital admission, a similar figure to previous reports (S R Palmer and J Corson, unpublished data). ${ }^{13}$

Though the reduction in mortality was not statistically significant, it was substantial and was unlikely to have been due to chance. Firstly, the same trend was noted in all three health districts and was also observed in a fourth health district outside this study. ${ }^{23}$ Secondly, the trend was more pronounced when only patients with a haemorrhagic rash (and therefore with a worse prognosis) were analysed. Thirdly, delay in starting treatment has been widely believed to be an important factor contributing to death in meningococcal disease $\mathrm{e}^{15-172+25}$; the prompt initiation of parenteral treatment with an effective antibiotic might reasonably be expected to have a favourable influence on outcome.

High circulating levels of endotoxin and cytokines are closely correlated with mortality in meningococcal disease. ${ }^{26-28}$ Though exposure of meningococci to high concentrations of penicillin in vitro may cause increased liberation of endotoxin ${ }^{29} 30$ and therefore could cause clinical deterioration, administration of antibiotics to patients with meningococcal disease has been associated with an immediate fall in plasma endotoxin concentrations. ${ }^{26}$ 
Almost 20 years ago Goldacre noted that the case fatality rate in bacterial meningitis was lower in patients given antibiotics before being admitted to hospital. ${ }^{31}$ Oral and parenteral treatment were not differentiated in this study, however, and most treatment was probably by the oral route. Some of our patients received oral antibiotics, but we did not analyse this data because a number of different agents had been used, the duration of treatment had varied, compliance could not be assessed, and many children who took antibiotics for only a short period before admission were already vomiting.

Similarly, we could not exclude the possibility that general practitioners who gave antibiotics may have arranged more rapid admission to hospital, nor that hospital treatment might have been initiated more promptly when the general practitioner had already made a provisional diagnosis of meningococcal disease.

\section{BACTERIOLOGICAL INVESTIGATIONS}

Treatment with parenteral antibiotics before admission almost always rendered subsequent blood cultures sterile. Cerebrospinal fluid was the specimen most likely to confirm the diagnosis, whether or not antibiotics had been given. The lesser effect of antibiotic treatment on cerebrospinal fluid microscopy and culture than on blood culture was presumably due to the additional time taken for bactericidal levels of benzylpenicillin to be achieved in lumbar cerebrospinal fluid.

Though nasopharyngeal swabs yielded meningococci in only about $40 \%$ of cases, the positivity rate was unaffected by preadmission antibiotic treatment. As meningococci are thought to reach the bloodstream through the nasopharynx in most cases ${ }^{32}{ }^{3} \mathrm{p} " 3$ it is not surprising that nasopharyngeal meningococci are almost always indistinguishable from strains isolated from deep sites. ${ }^{203435} \mathrm{~A}$ throat or pernasal swab from the index case should therefore be obtained as a routine in suspected meningococcal disease and is particularly important when parenteral antibiotics have been given before admission or when a lumbar puncture is not undertaken.

\section{PREVALENCE OF ADMINISTRATION OF ANTIBIOTICS} BEFORE ADMISSION

The use of parenteral antibiotics before patients with suspected meningococcal disease are admitted to hospital has been encouraged in all three health districts. In Gloucester health district the department of public health medicine has issued regular circulars on meningococcal disease to general practitioners since 1982. This may have accounted for the sizeable increase in the proportion of cases being given such treatment. Nevertheless, despite the chief medical officer's letter to all doctors in the United Kingdom in 1988 , issued to enhance awareness of meningococcal disease and advising giving parenteral antibiotic treatment before admission to hospital, in each district fewer than half the patients diagnosed after this date were given such treatment by their general practitioner. Parenteral penicillin was rarely given in the absence of a rash, even when patients had symptoms or signs of meningitis.

Of 180 general practitioners in the Manchester area who were surveyed within four weeks of the chief medical officer's letter in 1988, only 56 of 115 respondents carried parenteral penicillin in their emergency bags. ${ }^{36}$ General practitioners may have eschewed the use of parenteral antibiotics in patients with meningitis because confusing cerebrospinal fluid findings may result, ${ }^{37}$ although this risk has probably been overstated $^{3839}$ and there is little value in a confirmed diagnosis if, as a consequence of delayed treatment, the patient has died.
General practitioners may also fear administering an inappropriate agent if the diagnosis is not subsequently confirmed, or inducing an anaphylactic reaction. The difficulties in diagnosing meningococcal disease are well known: early symptoms are non-specific, ${ }^{13}$ and rashes present at the first examination often lack any haemorrhagic component. ${ }^{40}$ Little harm will be done, however, if benzylpenicillin is given and an alternative diagnosis is subsequently established. Histories of penicillin "allergy" are seldom confirmed ${ }^{41}$; if anaphylaxis is thought to be a risk then chloramphenicol, which must be given intravenously, is a suitable alternative. Before reconstitution both antibiotics are stable for at least two years in the emergency bag.

As have other series, ${ }^{514}$ we found higher mortality in infants and in patients aged over 30 . General practitioners saw fewer skin rashes in these patients, and parenteral antibiotic treatment before admission was less likely. Meningococcal disease may be harder to diagnose in these age groups; Goldacre noted that bacterial meningitis was less likely to be suspected by general practitioners in very young children. ${ }^{31}$ General practitioners should be particularly alert to the possibility of meningococcal disease in both infants and older patients.

Prevention of meningococcal disease by universal immunisation is not feasible at present. Therefore public health measures which improve awareness of the disease and which may reduce mortality by encouraging early diagnosis and treatment remain important. Greater use of parenteral antibiotic treatment before patients are admitted to hospital can be achieved by means of frequent reminders to general practitioners; we have shown that such treatment is accompanied by reduced mortality. The early use of benzylpenicillin, preferably intravenously, when meningococcal disease is suspected is a simple and economic measure that could be implemented in most countries. It should be accompanied by urgent transfer of the patient to hospital. Public health physicians and medical microbiologists should inform general practitioners regularly of local trends in meningococcal disease and remind them of the varied presentations of the disease and of the value of early treatment. All family doctors should carry benzylpenicillin in their emergency bags and should be ready to use it.

We acknowledge gratefully the assistance of the staff of the Gloucester, Plymouth, and Bath medical records departments; the staff of the Plymouth Medical Audit Office; and our secretaries. The technical staff of the public health laboratories in each of the three districts have provided a skilled and dedicated emergency diagnostic service over $\mathrm{N}$ many years. We also thank Dr D M Jones, Meningococcal Reference Laboratory, Manchester, who made available agesex data on patients with meningococcal disease; Dr F A Majeed, department of public health medicine, Gloucester Health Authority, for statistical advice; and the National Meningitis Trust, which provided financial support.

1 Jones DM, Kaczmarski EB. Meningococcal infections in England and Wales: report of the Meningococcal Reference Laboratory for 1990. Communicable report of the Meningococcal
Disease Report 1991;1:R76-8.

2 Department of Health. Immunisation against infectious disease 1990. London: HMSO, 1990:166-72.

3 Lieberman JM, Greenberg DP, Ward JI. Prevention of bacterial meningitis vaccines and chemoprophylaxis. Infect Dis Clin N Am 1990;4:703-29.

4 Bjune G, Hoiby EA, Gronnesby JK, Arnesen O, Fredriksen JH, Halstensen A, et al. Effect of outer membrane vesicle vaccine against group B meningococcal disease in Norway. Lancet 1991;338:1093-6.

5 Abbott JD, Jones DM, Painter MJ, Young SEJ. The epidemiology of meningococcal infections in England and Wales, 1912-1983. I Infect 1985;11:241-57.

6 Goldacre MJ, Miller DL. Completeness of statutory notification for acute bacterial meningitis. $B M \mathcal{F}$ 1976;ii:501-3.

7 Cartwright KAV, Stuart JM, Noah ND. An outbreak of meningococcal disease in Gloucestershire. Lancet 1986;ii:558-61.

8 Harvey IM, Palmer SR, Peters TJ. Meningitis: can we trust the statistics? Health Trends 1989;21:73-6.

9 DeVoe IW. The meningococcus and mechanisms of pathogenicity. Microbiol Rev 1982;46:162-90.

10 Fallon RJ, Brown WM, Lore W. Meningococcal infections in Scotland 1972-82. F Hyg (Camb) 1984;93:167-80. 
11 Niklasson P, Lundbergh P, Strandell T. Prognostic factors in meningococcal disease. Scand $\mathcal{F}$ Infect Dis 1971;3:17-25.

2 Toews WH, Bass JW. Skin manifestations of meningococcal infection. An immediate indicator of prognosis. Am F Dis Child 1974;127:173-6.

13 Tonjum T, Nilsson F, Bruun JN, Haneberg B. The early phase of meningococcal disease. NIPH Ann 1983;6:175-81.

4 Banks HS. Meningococcosis. A protean disease. Lancet 1948;ii:635-40, $677-81$

15 Slack J. Deaths from meningococcal infection in England and Wales in 1978. I R Coll Physicians Lond 1982;16:40-4.

16 Talan DA, Hoffman JR, Yoshikawa TT, Overturf GD. Role of empiric antibiotics prior to lumbar puncture in suspected bacterial meningitis: state

17 Oakley JR, Stanton AN. Meningococcal infections during infancy: confidential enquiries into 10 deaths. BMF 1979;ii:468-9.

18 Department of Health and Social Security. Meningococcal infection: meningitis and septicaemia. London: DHSS, 1988. (PL/CMO(88)2.)

19 Drugs for the doctor's bag 1989. Drug Ther Bull 1989:27:17-9.

20 Abramson JS, Spika JS. Persistence of Neisseria meningitidis in the upper respiratory tract after intravenous antibiotic therapy for systemic meningococcal disease. F Infect Dis 1985;151:370-1.

21 Jones DM, Kaczmarski EB. Meningococcal infections in England and Wales: report of the Meningococcal Reference Laboratory for 1991. Communicable Disease Report 1992;2:R61-3.

22 Dean AG, Dean JA, Burton JH, Dicker RC. Epi Info, Version 5: a wordprocessing, database, and statistics program for epidemiology on microcomputers. Atlanta: Centers for Disease Control, 1990.

23 Strang JR, Pugh EJ. Meningococcal infections: reducing the case fatality rate by giving penicillin before admission to hospital. $B M \mathcal{J}$ 1992;305:141-3.

24 Talan DA, Guterman JJ, Overturf GD, Singer C, Hoffman JR, Lambert B. Analysis of emergency department management of suspected bacterial Analysis of emergency department managen

25 Gedde-Dahl TW, Hoiby EA, Brandtzaeg P, Eskerud JR, Bovre K. Some arguments on early hospital admission and treatment of suspected meningococcal disease cases. NIPH Ann 1990;13:45-60.

26 Brandtzaeg P, Kierulf P, Gaustad P, Skulberg A, Bruun JN, Halvorsen S, et al. Plasma endotoxin as a predictor of multiple organ failure and death in systemic meningococcal disease. F Infect Dis 1989;159:195-204.

27 Waage A, Halstensen A, Espevik T. Association between tumour necrosi factor in serum and fatal outcome in patients with meningococcal disease. Lancet 1987;i:355-7.

28 Waage A, Brandtzaeg P, Halstensen A, Kierulf P, Espevik T. The complex pattern of cytokines in serum from patients with meningococcal septic shock. Association between interleukin 1 , interleukin 6, and fatal outcome. f Exp Med 1989;169:333-8.

29 Andersen BM, Solberg $\mathrm{O}$. The endotoxin-liberating effects of antibiotics on meningococci in vitro. Acta Pathologica et Microbiologica Scandinavica $(B)$ 1980;88:231-6

30 Mellado MC, Rodriguez-Contreras R, Mariscal A, Luna JD, Delgado Rodriguez M, Galvez-Vargas R. Effect of penicillin and chloramphenicol on the growth and endotoxin release by $\mathrm{N}$ meningitidis. Epidemiol Infect the growth and $1991 ; 106: 283-8$.

31 Goldacre MJ. Acute bacterial meningitis in childhood: aspects of prehospita care in 687 cases. Arch Dis Child 1977;52:501-3.

32 Edwards EA, Devine LF, Sengbusch $\mathrm{CH}$, Ward HW. Immunologica investigations of meningococcal disease. III. Brevity of group $\mathrm{C}$ acquisition prior to disease occurrence. Scand f Infect Dis 1977;9:105-10.

33 Stephens DS, Farley MM. Pathogenic events during infection of the huma nasopharynx with Neisseria meningitidis and Haemophilus influenzac. Rev Infect Dis 1991;13:22-33.

34 Cartwright KAV, Jones DM. Value of throat swabs from index cases of meningococcal meningitis. $\mathcal{F}$ Clin Pathol 1990;43:438.

35 Sippel JE, Girgis NI. Throat culture from patients with meningococcal meningitis. F Clin Pathol 1990;43:610-1.

36 Ong ELC, Dunbar EM. Antibiotics carried in general practitioners' emergency bags. $B M 7$ 1988;297:901

37 Converse GM, Gwaltney JM, Strassburg DA, Hendley JO. Alteration of cerebrospinal fluid findings by partial treatment of bacterial meningitis. I Pediatr 1973;83:220-5

38 Jarvis $\mathrm{CW}$, Saxena KM. Does prior antibiotic treatment hamper the diagnosis of acute bacterial meningitis? Clin Pediatr 1972;11:201-4.

39 Partially treated meningitis. Lancet $1974 ; \mathrm{i}: 55-6$.

40 Baxter P, Priestley B. Meningococcal rash. Lancet 1988;i:1166-7.

41 Surtees SJ, Stockton MG, Gietzen TW. Allergy to penicillin: fable or fact? BMF 1991;302:1051-2.

Accepted 15 May 1992)

\author{
Michael Sharpe, Keith Hawton, Valerie Seagroatt, Geoffrey Pasvol
}

\title{
Follow up of patients presenting with fatigue to an infectious diseases clinic
}

\section{University of Oxford, Oxford}

Michael Sharpe, clinical tutor, department of psychiatry Keith Hawton, clinical lecturer, department of psychiatry

Valerie Seagroatt, statistician, unit of health care epidemiology, department of public health and primary care

\section{Nuffield Department of} Medicine, John Radcliffe Hospital, Oxford Geoffrey Pasvol, consultant physician

Correspondence to: Dr M Sharpe, University Department of Psychiatry, Warneford Hospital, Oxford OX3 7JX.

$B M \mathcal{F} 1992 ; 305: 147-52$

\section{Abstract}

Objectives-To determine the symptomatic and functional status during follow up of patients referred to hospital with unexplained fatigue and to identify patient variables associated with persistent functional impairment.

Design-Follow up by postal questionnaire six weeks to four years (median 1 year) after initial clinical assessment of patients referred to hospital during 1984-8.

Setting - Infectious diseases outpatient clinic in a teaching hospital.

Patients -200 consecutive patients with fatigue of uncertain cause for at least six weeks; 177 fulfilled the inclusion criteria.

Main outcome measures-Findings at initial assessment; current symptoms, beliefs about the cause of illness, coping behaviours emotional disorder, social variables including membership of self help organisations, and degrees of recovery and functional impairment from questionnaire responses.

Results-144 (81\%) patients returned completed questionnaires. Initial assessment did not indicate the cause of fatigue, other than preceding infection. The proportion of patients with functional impairment was significantly smaller with longer follow up $(33 \%(11 / 33)$ at two to four years, $73 \%(29 / 40)$ at six weeks to six months; $\chi^{2}$ for trend $=12 \cdot 5, \mathbf{d f}=1$; $\mathbf{p}<\mathbf{0 . 0 5}$ ). Functional impairment was significantly associated with belief in a viral cause of the illness (odds ratio $=3.9 ; 95 \%$ confidence interval 1.5 to 9.9 ), limiting exercise $(3.2 ; 1.5$ to 6.6$)$, avoiding alcohol $(4.5 ; 1.8$ to 11.3$)$, changing or leaving employment $(3.1 ; 1.4$ to 6.9$)$, belonging to a self help organisation $(7.8 ; 2.5$ to 23.9$)$, and current emotional disorder $(4 \cdot 4 ; 2 \cdot 0$ to $9 \cdot 3)$.
Conclusions-Short term prognosis for recovery of function was poor but improved with time. Most patients had made a functional recovery by two years after initial clinic attendance. Impaired functioning was more likely with certain patient characteristics. Prospective studies are required to clarify whether these associations are the consequences of a more disabling illness or indicate factors contributing to impaired function.

\section{Introduction}

In recent years there has been renewed interest in the causes and management of the symptom of fatigue. Although fatigue is a symptom of many medical conditions, identifiable organic disease is rarely found in patients referred to hospital with fatigue as a major complaint. ${ }^{12}$ The fatigue is then considered to be "idiopathic." Clinical concern has focused on patients whose fatigue is idiopathic, persistent, and associated with impaired physical and mental functioning, who have been referred to as having a "chronic fatigue syndrome" if the fatigue has been present for at least six months. ${ }^{3}$ The patient group thus defined is almost certainly aetiologically and prognostically heterogeneous. Several more specific syndromes have been proposed, including more restrictively defined chronic fatigue syndromes, ${ }^{45}$ postviral fatigue syndrome,${ }^{6}$ and myalgic encephalomyelitis. ${ }^{7}$ Although each has its advocates, none of these specific syndromes has yet been shown to have clinical utility.

The literature includes several studies of patients with idiopathic fatigue, most of which have selected patients according to one of the above criteria. However, there is still a paucity of information concerning unselected patients referred to non-specialist units. The patient samples of previous studies have been 